\title{
LEMBRANÇAS DE MULHERES EM ARMAS: RELATOS MEMORIALÍSTICOS SOBRE O FRONT
}

\author{
Joyce Rodrigues Silva Gonçalves ${ }^{1}$
}

RESUMO: Este trabalho se propõe fazer uma breve análise do livro A guerra não tem rosto de mulher, de Svetlana Aleksièvitch, a partir da perspectiva dos estudos sobre o testemunho e suas relações com a memória, considerando ainda as questões de gênero presentes na obra. Ademais, serão pontuadas algumas problemáticas inerentes às narrativas de memória, como a lembrança, o esquecimento, o silenciamento, a autoria, a ficção e as experiências vividas. Este estudo é parte de uma pesquisa de Doutorado em andamento na Faculdade de Letras da Universidade Federal de Minas Gerais, sendo um recorte de um dos capítulos que compõem a Tese. Os aportes teóricos que orientam o texto são proposições de autores como Philippe Lejeune, Michel Foucault, Michael Pollak, Enrique Serra Padrós e Márcio Seligmann-Silva. Palavras-chave: Memória; Testemunho; Gênero; Guerra; Mulheres.

ABSTRACT: This paper intends to make a brief analysis of Svetlana Aleksievitch's book War's Unwomanly Face, from the perspective of the studies on testimony and its relations with memory, considering also the gender issues present in the work. In addition, some problems inherent to memory narratives will be punctuated, such as remembering, forgetting, silencing, authorship, fiction and lived experiences. This study is part of a PhD research in progress at the Faculty of Letras of the Federal University of Minas Gerais, being a clipping of one of the chapters of the Thesis. The theoretical contributions that guide the text are propositions of authors such as Philippe Lejeune, Michel Foucault, Michael Pollak, Enrique Serra Padrós, and Márcio Seligmann-Silva.

KEYWORDS: Memory; Testimony; Gender; War; Women.

Nem todos se decidem a escrever suas memórias, e nem todos conseguem confiar ao papel seus sentimentos e reflexões. "As lágrimas atrapalham..." (A. Burakova, sargento, operadora de rádio). Svetlana Aleksiévitch

1Doutoranda em Letras pelo Programa de Pós-graduação em Estudos Literários da UFMG. E-mail: joycerodriguesufmg@outlook.com 
Publicado na década de 1980, especificamente em 1985, A guerra não tem rosto de mulher, da bielorrussa Svetlana Aleksiévitch, foi traduzido do russo e publicado no Brasil em 2016, trazendo na capa o selo do Prêmio Nobel de Literatura conferido à autora em 2015. A obra traz a público relatos de mulheres soviéticas em uma perspectiva quase ou nada explorada sobre a participação feminina na Segunda Guerra Mundial. O livro é uma antologia polifônica em que a autora reúne testemunhos de mulheres que atuaram no front no contexto dessa guerra; para tal, Aleksiévitch percorreu mais de cem cidades ao redor da então União das Repúblicas Socialistas Soviéticas em busca dessas mulheres e de seus relatos memorialísticos sobre a guerra.

A guerra não tem rosto de mulher permite um diálogo entre os estudos sobre memória traumática com os estudos de gênero. Embora já bastante analisada e trabalhada em várias áreas do conhecimento, e mesmo no campo dos estudos literários, a Segunda Guerra Mundial continua sendo fonte para reflexões e trabalhos acadêmicos. O que a obra de Aleksiévitch traz de novo é a abordagem do assunto a partir de uma nova perspectiva que foge à tradição histórica, já que privilegia as percepções soviéticas da Segunda Guerra, em contraponto com a versão e a visão da guerra difundida pelo ocidente. Ademais, temos aqui uma mulher, que compila centenas de relatos de mulheres combatentes, quando os relatos e memórias de guerra são predominantemente masculinos ao longo da História. Svetlana Aleksiévitch desconstrói a imagem convencional da guerra, que geralmente é delineada como um grande evento histórico, político, de nacionalismo exaltado, e contempla as narrativas individuais que, não raro, contestam as versões oficiais dos documentos históricos. Pode-se perceber isso através das múltiplas vozes de mulheres na obra; ainda que inicialmente as jovens estivessem plenamente dispostas a guerrear, ao vivenciarem as experiências da guerra, a maioria passa a enxergá-la como a barbárie que de fato estava posta em suas vidas. Muitas externam suas considerações sobre a guerra, julgando-a desnecessária, brutal, e refletem como o ser humano se propõe e se dispõe a tal crueldade para com sua própria espécie.

A metodologia da história oral, adotada para a coleta dos testemunhos, demanda da autora certa articulação dos relatos pessoais das ex-combatentes, como é possível observar no decorrer das narrativas. Svetlana Aleksiévitch organiza as experiências dessas narradoras por temas, na maior parte das vezes, e proporciona a essas mulheres um espaço que até então lhes foi negado, uma vez que foram negligenciadas nas narrativas oficiais das guerras, que contemplam, via de regra, as vozes e as experiências masculinas.

Um problema se faz presente na análise de A guerra não tem rosto de mulher, algo que não se pode ignorar, que é a autoria dos registros e a(s) autoria(s) das memórias. A autoria do livro não coincide, na maior parte das vezes, com os sujeitos que enunciam, que rememoram suas experiências traumáticas. Philippe Lejeune em seu O pacto autobiográfico (2014), afirma que o contrato de leitura deve ser estabelecido pelo autor do texto para com o leitor, e que o pacto é firmado com o nome do autor na capa do livro. Em A guerra não tem rosto de mulher, o pacto é evidentemente firmado, mas um pouco às avessas, já que a autora da obra não é a dona das memórias, mas uma porta-voz das mulheres ex-combatentes. Isso é estabelecido desde o início da obra, em seus pré-textos, e ao longo dela, nos comentários da própria autora em relação ao processo de coleta e registro das lembranças das mulheres guerreiras. 
A metodologia etnográfica adotada por Aleksiévitch nos faz pensar na escrita de uma "literatura em colaboração", ou "colaboração autobiográfica", utilizando expressões de Lejeune, em que a autoria é problematizada. O teórico, refletindo sobre "A autobiografia dos que não escrevem", um capítulo de sua obra citada acima, coloca em questão os registros escritos colhidos através de entrevistas gravadas e transformados em textos autobiográficos. A escrita da autora bielorrussa é uma escrita de outras mulheres, ou seja, "uma escrita flutuante, uma forma autobiográfica sem um sujeito que a fundamente, mas que, ao contrário, fundamenta em seu papel de sujeito aquele que a assume ou a quem ela foi atribuída" (LEJEUNE, 2014, p.140).

A noção de autoria, desde as reflexões de Michel Foucault, e retomada por Lejeune, se faz relevante nas autobiografias dos que não escrevem. A impressão causada é de que se tratam de textos sem autora(s), ou autoras fictícias, ou ainda, de ficionalização da autora, que assina a capa do livro, o que torna as narrativas, ou pelo menos suas análises, mais interessantes. Lejeune (2014, p. 143) chama a atenção para o fato de que tanto o "modelo" (que retoma suas memórias e concede a entrevista), quanto o redator, autor da publicação, têm a inclinação de acreditar ser o principal, ou até mesmo o único autor do texto publicado. O autor observa que

Os jogos de ilusão engendrados por esse modo de trabalho não são reservados ao leitor, que seria enganado por eles: o modelo e o redator podem ser eles próprios vítimas de uma vertigem ou alucinação. E é verdade que a "vida" em questão pertence a ambos - mas talvez também, pela mesma razão, não pertença nem a um, nem a outro: a forma literária e social do relato de vida, que preexistia ao empreendimento, não seria a "autora" dos dois? (LEJEUNE, 2014, p. 143)

No caso dos registros de Svetlana Aleksiévitch, o problema talvez não seja tão complexo, considerando que não se trata de apenas um modelo, mas de centenas deles, o que afastaria um pouco essa possível vertigem. De todo modo, a discussão sobre a autoria continua latente, uma vez que a autora do livro não coincide com as autoras das memórias "cedidas", nesse caso, como aponta Lejeune (2014, p. 138) sobre a questão, “... [o] esforço de memória e o esforço de escrita são obras de pessoas diferentes, dentro de um processo de diálogo que poderá deixar vestígios orais e escritos".

Michel Foucault (2011, p. 268), em seu texto O que é um autor, discute a questão ao afirmar sobre a "função-autor" que

[e]la não é definida pela atribuição espontânea de um discurso a seu produtor, mas por uma série de operações específicas e complexas; ela não remete pura e simplesmente a um indivíduo real, ela pode dar lugar simultaneamente a vários egos, a várias posições-sujeito que classes diferentes de indivíduos podem vir a ocupar.

O que ocorre em A guerra não tem rosto de mulher é um exemplo do que fala Foucault sobre a autoria. Há vozes de sujeitos em uma posição específica, de uma determinada clas- 
se (mulheres que combateram no front) que testemunham suas vivências na guerra e que tomam seu lugar de fala através dos registros da jornalista que se propôs a privilegiar essas narrativas de memórias. Não falamos necessariamente de um discurso coletivo, embora também possa ser considerado, mas essas narradoras "se encontram em uma posição 'transdiscursiva"” (FOUCAULT, 2011, p. 269), em um híbrido de memórias individuais, memória coletiva e memória histórica.

Em vários desses relatos, ainda, ocorre um movimento de não escrita ou não revelação de identidades por opção, algumas narradoras solicitam à entrevistadora/autora do livro que seus nomes sejam modificados na publicação, ou que suas identidades permaneçam anônimas, como neste exemplo: "Não escreva meu nome. Melhor não... [Klávdia S-va, francoatiradora]". (ALEKSIÉVITCH, 2016, p. 306).

Ao problematizar a situação de registro de memórias dos que não escrevem, seja por falta de domínio da língua escrita, seja por falta de iniciativa, ou por um silenciamento imposto (como parece ser o caso da maioria das mulheres soviéticas que lutaram no front na Segunda Guerra), Lejeune (2014, p. 154) aponta um outro fator que atravessa esse método, que é a relação entre relato de vida e classes sociais, e pontua que

[o] vivido das classes dominadas não está, na verdade, em suas próprias mãos. Como sugere Pierre Bourdieu, "as classes dominadas não falam, fala-se delas". Seu vivido é estudado de cima, de um ponto de vista econômico e político [...] imaginado no discurso jornalístico e romanesco das classes dominantes.

A observação do autor é bastante pertinente se aplicada ao caso das ex-combatentes soviéticas, já que ao longo de décadas suas memórias foram suprimidas e suas vozes silenciadas. Primeiro, essas mulheres pertenciam quase totalmente a uma classe dominada, de operários e camponeses. Depois porque o fato de serem mulheres nunca pareceu tão relevante nas narrativas de guerras, ao contrário, tradicionalmente elas se limitavam ao ambiente doméstico, cuidando do lar, dos filhos e dos maridos.

Sobre a estrutura da obra, podemos observar que é composta por pequenos relatos, na maioria das vezes, lembranças sintetizadas mesmo em uma linha, um ou dois parágrafos. Os mais longos testemunhos ocupam poucas páginas do livro. Inicialmente podemos ter a impressão de que as memórias dessas mulheres são registradas aleatoriamente, até mesmo causa a sensação de uma escrita caótica, sem muitas amarras. Todavia, com a evolução da leitura, pode-se concluir que a organização dos testemunhos é pautada por temas. Svetlana seleciona as experiências vividas pelas soviéticas que compartilham as mesmas questões, em que surgem percepções semelhantes em relação a alguns pontos, é o que podemos pensar como um fio que une os relatos e tece uma espécie de patchwork, formando, afinal, um mosaico muito bem definido das imagens da guerra descritas pelas ex-combatentes.

Outro elemento que se faz marcante na obra em análise é o fato de que a maioria das testemunhas do front relatam suas experiências somente após décadas das experiências vividas. Muitas delas já consideradas idosas. Sabemos que o ato de rememoração já é quase sempre lacunar, mas se tratando de várias décadas dos fatos vivenciados, o processo mnemônico se torna ainda mais nebuloso. Obviamente, algumas dessas memórias permanecem 
nítidas ao longo do tempo, o que é conhecido neurologicamente, psicologicamente, como memória de longo prazo; entretanto, muitos detalhes são completamente apagados e alguns acontecimentos se tornam ao menos embotados.

O processo de rememoração ocorre de modos diversos de acordo com a situação de retomada dessas lembranças, em que alguns critérios devem considerados. O sujeito que se lembra de uma experiência não é exatamente o mesmo que a vivenciou. É um sujeito atravessado pelo tempo, pelas suas próprias transformações pessoais e psicossociais. Lembrar depois de certa idade torna-se, então, um desafio para o indivíduo que se propõe realizar ao menos uma tentativa de resgate de suas experiências antigas, como podemos observar no excerto que se segue, em que Svetlana (ALEKSIÉVITCH, 2016, p. 179), reflete:

O que fica gravado na memória, mais do que tudo? Lembro de uma voz humana baixa, muitas vezes atônita. Uma pessoa que experimenta o espanto diante de si mesma, diante do que aconteceu com ela. O passado desapareceu, foi ofuscado por um turbilhão quente e se escondeu, mas a pessoa ficou. Ficou em meio à vida cotidiana. Tudo ao seu redor é costumeiro, menos a memória. Eu também me transformo em testemunha. Testemunha daquilo que as pessoas se lembram, e de como se lembram, do que querem falar, e do que tentam esquecer ou afastar para o canto mais distante da memória. Fechar a cortina. De como elas se desesperam na busca pelas palavras, e mesmo assim querem reconstituir o que desapareceu, na esperança de que a distância permita captar o sentido completo do passado. Ver e entender o que não viram e o que não entenderam na época. Lá. Examinam a si mesmas, se reencontram de novo. Muitas vezes já são duas pessoas - aquela e essa, uma jovem e uma velha. A pessoa durante a guerra e a pessoa depois da guerra. Bem depois da guerra. Sou o tempo todo tomada pela sensação de que estou escutando duas vozes ao mesmo tempo.

Em determinadas passagens do texto aparecem reflexões de algumas dessas mulheres e a avaliação que fazem em relação ao que foram no passado, à postura que tinham diante dos riscos que corriam e da coragem própria da juventude, como no excerto seguinte: "Os velhos têm medo da morte, já os jovens riem dela. São imortais! Eu não acreditava que podia morrer..." [Anna Semiónova Dubróvna-Tchekunova, primeiro-tenente da guarda, piloto] (ALEKSIÉVITCH, 2016, p. 88). E, geralmente, após se verem já idosas, a autorreflexão sobre os atos de coragem traz uma atmosfera muitas vezes de arrependimento de alguns feitos, ou, pelo menos, de culpa ao reconhecerem a barbárie da qual também faziam parte, como no relato abaixo:

"Felizmente eu... Eu não vi as pessoas que matei..., Mas... Mesmo assim... Agora entendo que matei. Penso nisso... Porque... Porque fiquei velha. Rezo por minha alma. [Vera Boríssovna Sapguir, sargento, operadora de artilharia anti-aérea]" (ALEKSIÉVITCH, 2016, p. 105).

Ademais, o próprio envelhecimento psíquico, não necessariamente atrelado a uma longa passagem do tempo, causado pela experiência da guerra, também se faz presente nas 
considerações de algumas dessas mulheres. Os efeitos traumáticos são tão intensos que envelhecem os sujeitos logo após os eventos violentos, como observa uma delas:

A alma de uma pessoa envelhece durante a guerra. Depois da guerra, nunca mais fui jovem... isso é o mais importante. É o que eu acho... Agora, me lembro de tudo e parece que não era eu, e sim alguma outra garota... [Olga Iákovlevna Oméltchenko, enfermeira-instrutora de uma companhia de fuzileiros] (ALEKSIÉVITCH, 2016, p. 188).

As memórias traumáticas não se restringem à violência da guerra em si, mas também à violência física, intimamente ligada ao corpo feminino. O estupro era uma brutalidade frequente entre as mulheres. Tanto sofriam as soviéticas, quanto as alemãs, quando as forças aliadas invadiram o território da Alemanha. Em A guerra não tem rosto de mulher, a crítica e a denúncia são contra o ato bárbaro, perpetrado contra a mulher de modo geral. Os relatos nesse sentido são de testemunhos da devastação humana desde o nível macro, na totalidade do evento em si, ao micro, se assim podemos chamar a intimidade e a sexualidade do indivíduo.

Quando tomamos a memória como objeto de estudo, é imprescindível considerarmos algumas questões inerentes ao tema, como a lembrança, o esquecimento, o silêncio, o silenciamento. Sabemos que como mecanismo psíquico, a memória é seletiva; lembrar significa também esquecer. Em A guerra não tem rosto de mulher, podemos observar em alguns relatos a presença desses elementos, em que as mulheres que lembram deixam transparecer a seletividade de suas memórias em seus testemunhos. Em outros, entretanto, afirmam que é impossível se esquecerem das experiências traumáticas, como no relato de Olga Vassílievna (ALEKSIÉVITCH, 2016, p. 143): “Não somos capazes de esquecer, não está em nosso poder (...) eu gostaria de esquecer. Eu queria viver ao menos um dia sem a guerra. Sem a nossa memória dela... nem que fosse um dia só.”. E nesta observação de Svetlana (ALEKSIÉVIT$\mathrm{CH}, 2016$, p. 159-160) em que a autora descreve a recusa da lembrança por parte de algumas mulheres:

Em todo o período de busca, houve algumas recusas desesperadas: 'Não, é como um pesadelo... Não consigo! Não vou!. Ou "Não quero me lembrar! Não quero! Passei muito tempo esquecendo.... “[...] é terrível lembrar, mas é mais terrível ainda não lembrar.

Portanto, há sempre um embate entre a memória e o esquecimento; ainda que pertençam ao mesmo campo de reminiscências.

O processo de rememoração de eventos traumáticos através do discurso, neste caso, oral, traz ao indivíduo a possibilidade terapêutica de tentar reorganizar os fatos passados, de se compreender como sujeito e de descobrir e/ou (re)constituir sua identidade. Todavia, relembrar acontecimentos violentos e dolorosos também pode significar, como geralmente ocorre, reviver a dor, sentir novamente a ferida se abrindo. Para Enrique Serra Padrós, em seu texto "Usos da memória e do esquecimento na História” (PADRÓS, 1991, p. 86), “[e] 
nquanto não se encara o passado de frente, a ferida não termina de cicatrizar.”. Apesar da assertiva do autor, há a possibilidade de que, mesmo encarando esse passado e reelaborando o trauma vivido, a ferida pode não cicatrizar, pode ser que o sujeito leve consigo até o fim da vida essa chaga aberta, que ao menor toque ou esbarrão na memória, volta a dilacerar dentro de si.

No mesmo texto, entretanto, Padrós afirma que há, além do direito de lembrar, também o direito de esquecer. O direito à lembrança estaria relacionado à necessidade de se reafirmar que eventos traumáticos não devem se repetir; já o direito ao esquecimento significa que o indivíduo pode optar por não se submeter às asperezas das memórias do trauma.

Além dos embates entre lembranças e esquecimentos do indivíduo, há uma disputa de memórias que se faz presente em âmbito histórico e social. Michael Pollak, em seu texto "Memória e identidade social", discorre sobre o que ele chama de "memória organizadíssima", que é a memória nacional, tradicionalmente registrada nos documentos oficiais da nação. O autor afirma que a memória é, portanto, um fenômeno construído, é um trabalho de organização. Em outro texto, "Memória, esquecimento, silêncio", o mesmo autor continua suas reflexões sobre o tema e pontua que,

[a]o privilegiar a análise dos excluídos, dos marginalizados e das minorias, a história oral ressaltou a importância de memórias subterrâneas que, como parte integrante das culturas minoritárias e dominadas, se opõem à "Memória oficial", no caso a memória nacional. Num primeiro momento, essa abordagem faz da empatia com os grupos dominados estudados uma regra metodológica e reabilita a periferia e a marginalidade. Ao contrário de Maurice Halbwachs, ela acentua o caráter destruidor, uniformizador e opressor da memória coletiva nacional. Por outro lado, essas memórias subterrâneas que prosseguem seu trabalho de subversão no silêncio e de maneira quase imperceptível afloram em momentos de crise em sobressaltos bruscos e exacerbados. A memória entra em disputa. Os objetos de pesquisa são escolhidos de preferência onde existe conflito e competição entre memórias concorrentes. (POLLAK, 1989, p. 4)

Pollak chama a atenção para as vozes que surgem, então, das fissuras do discurso oficial da nação, em que as memórias de grupos minoritários, como é o caso das mulheres guerreiras soviéticas, se chocam com a memória nacional, é quando a memória entra em disputa.

As memórias dos grupos marginalizados, que não encontram espaço legítimo na História da nação, chamadas por Pollak de "memórias subterrâneas", são aquelas que emergem como contraponto da História oficial, geralmente manifestas através da literatura, de depoimentos, entrevistas, testemunhos que acabam se tornando discursos literários.

Na mesma linha de Michael Pollak, Enrique Serra Padrós aponta para as memórias subterrâneas chamando-as de "desmemória", ou "memórias confiscadas". O autor (PADRÓS, 1991, p. 80) afirma que a memória, além de individual, “[...] passa a ser um fator fundamental de identidade e de suporte dos sujeitos coletivos.”. Padrós pontua, ainda, que a memória expressa uma relação de poder, que hierarquiza uma sociedade em todos os seus 
aspectos, sejam políticos, culturais, e de classe. Detêm o poder aqueles que conseguem manipular os usos da memória e seus registros que oficializam os fatos históricos, em um processo que ele chama de "memória reciclada". Do mesmo modo, Pollak fala sobre "memória enquadrada", em que se publica aquilo que é conveniente ou que é permitido ser divulgado de acordo com os interesses dos grupos detentores de poder político, principalmente. Outro exemplo de enquadramento da memória seriam as produções cinematográficas que representam eventos violentos e memórias traumáticas. Os filmes imprimem um determinado enfoque de acordo com as intenções de seus produtores.

Quando os grupos marginalizados, relegados ao esquecimento histórico, encontram oportunidades de testemunharem suas vivências, esses relatos servem de depoimento, de denúncia, em objeção aos discursos e memórias manipuladas, recicladas. Entretanto, esses relatos não ocorrem de maneira plena, sem nenhum tipo de problema em torno deles, já que o gênero testemunho é cercado de questões que devem ser levadas em conta, desde o caráter lacunar da memória até a autoficção.

De acordo com Márcio Seligmann-Silva (2013, p. 8),

[o] testemunho deve ser compreendido tanto no sentido jurídico e de testemunho histórico, como também no sentido de "sobreviver" [...], de ter-se passado por um evento-limite, radical, passagem essa que foi também um "atravessar" a "morte", que problematiza a relação entre a linguagem e o real.

Em A guerra não tem rosto de mulher, os testemunhos das ex-combatentes configuram-se nesses sentidos apontados por Seligmann-Silva e cumprem sua função através de vozes, anônimas ou não, com nomes fictícios ou verdadeiros. Narrativas de vida que encontram na literatura do trauma um meio de se colocarem e se fazerem conhecidas, à revelia daqueles que controlam, que dominam os discursos oficiais da nação.

Em relação à disposição das narrativas na obra, organizada basicamente em sessões temáticas, não explicitamente, nem com uma divisão/organização muito marcada, Svetlana Aleksiévitch reúne relatos em torno de questões como aborto, menstruação, estupro, maternidade, amor e casamentos em meio à guerra, bondade e compaixão para com os seus e até para com os inimigos, vaidade feminina, perda do feminino, tanto na aparência física, quanto no ciclo biológico, sexo, suicídio, enfim, temas que norteiam as narrativas de modo que as memórias dessa guerra transcendem os relatos típicos masculinos registrados pela História oficial. Esses testemunhos não se restringem à violência e à barbárie como conhecemos através dos livros, do cinema e das artes de modo geral, mas conferem à guerra um olhar muito particular, até então pouco explorado.

Questões ligadas ao corpo e suas relações com a memória perpassam quase toda a obra de Svetlana Aleksiévitch, o que é um dado bastante importante se considerarmos as concepções do feminino, tanto na perspectiva psicanalítica, quanto na sócio-cultural. O excerto abaixo, (ALEKSIÉVITCH, 2016, p. 81-82), exemplifica uma dessas questões:

Estava esperando meu segundo filho... Tinha um menino de dois anos e estava grávida. E aí, veio a guerra. E meu marido no front. Fui para a casa dos meus pais e fiz... É, entende? Um aborto. Apesar de na época estar proibido... Como ia dar 
à luz? Num mar de lágrimas... Na guerra! Como dar à luz em meio à morte? Me formei num curso de criptografia e fui mandada para o front. Queria me vingar por minha filhinha, me vingar por não ter tido. Minha menina. Ia ser uma menina... Pedi para ir para a linha de frente. Me deixaram no estado-maior... (Liubov Arkadievna Tchárnaia, segundo-tenente, criptógrafa).

Percebemos, no relato acima, além dos traumas sociais da guerra, um trauma tanto físico, quanto psicológico, que geralmente um aborto pode causar em uma mulher. $\mathrm{O}$ fato de Liubov Arkadievna Tchárnaia desejar se vingar pela filha que ela não pôde permitir vir ao mundo imerso na barbárie, é um vestígio do choque causado pelo fato, que décadas após ocorrido, é elencado por ela em seu testemunho.

Algo interessante que podemos observar em alguns relatos é que as mulheres entrevistadas não nomeiam a menstruação ao se referirem a esse fato natural. É como se, ao ocuparem o lugar de soldados, tivessem que abrir mão de sua natureza, inclusive biológica, como os exemplos que seguem abaixo (ALEKSIÉVITCH, 2016, p. 81, 252):

Cederam-me a medalha e no mesmo dia fomos cumprir uma tarefa. Pela primeira vez na vida me aconteceu... A nossa... Essa coisa das mulheres... Vi meu sangue e soltei um grito: “Fui ferida!” Junto conosco, os batedores, havia um enfermeiro, um homem já mais velho. Ele me disse: "Onde te feriram?" "Onde não sei... Mas estou sangrando...”. E ele me explicou, como um pai... (Albina Aleksándrovna Gantimúrova)

Estávamos andando e, atrás de nós começaram a aparecer manchas vermelhas na areia... Um rastro vermelho... Bem, era a... Nossa... Como você vai esconder isso? Os soldados vinham atrás e fingiam que não estavam notando nada... Não olhavam para os pés... As calças secavam no corpo e ficavam feito vidro. Cortavam. Faziam feridas, o tempo todo se sentia cheiro de sangue. Não nos davam nada... Ficávamos de guarda para ver quando os soldados penduravam as camisas nos arbustos. Surrupiávamos umas duas. Depois eles já adivinhavam, riam: "Subtenente, dê-nos outra camisa de baixo. As meninas pegaram as nossas". Não havia algodão e ataduras suficientes para os feridos... Para outros usos, então... Roupa de baixo feminina só apareceu uns dois anos depois, talvez. Usávamos cuecas e camisetas masculinas. Bem, estávamos andando... De botas! Os pés também estavam fritos. Estávamos andando. Seguimos até uma passagem, e lá as balsas estavam nos esperando. Chegamos à passagem e começaram a nos bombardear. Um bombardeio terrível; os homens correram para se esconder, cada um num lugar. Nos chamavam... Mas nós não escutávamos as bombas, não estávamos nem aí para as bombas, fomos rápido para o rio. Para a água... Água! Água! Sentávamos lá até lavar tudo... Debaixo de estilhaços... Veja como era... A vergonha dava mais medo do que a morte. E algumas garotas morreram na água... Talvez tenha sido a primeira vez que desejei ser homem... A primeira vez... (Maria Semiónovna Kaliberdá, sargento, comunicações) 
Ao lermos esses relatos, percebemos o constrangimento das mulheres guerreiras em relação aos seus corpos, mesmo tanto tempo após suas experiências de guerra. Em meio a um ambiente tão inóspito como um campo de batalha, essas mulheres ainda tinham que lidar com situações próprias do feminino como se não estivessem acontecendo. Eram "detalhes" que não podiam "atrapalhar" o serviço militar, as mulheres ali eram soldados, em um movimento ao mesmo tempo de anulação do próprio gênero e reafirmação dele, paradoxalmente, pois ora se colocavam tal como os homens, ora a natureza feminina era dominante.

A obra de Svetlana Aleksièvitch nos permite saber que o retorno das mulheres que sobreviveram às batalhas na Segunda Guerra aos seus países e a reinserção delas na sociedade não ocorreu de modo tranquilo, menos ainda heroico, como foi, predominantemente, o caso dos homens. Ao contrário, elas eram discriminadas, malvistas pelas outras mulheres que permaneceram em suas casas, afinal, que tipo de mulher é esse que vai à luta, literalmente? As mulheres na guerra frequentemente eram desejadas pelos homens, pelos esposos das outras. Os homens as viam como estranhas por ousarem ocupar os lugares legitimamente masculinos, como poderiam se relacionar com essas mulheres? Casarem-se com elas? Não seriam, possivelmente, submissas aos seus maridos.

Enfim, muitas delas não foram devidamente condecoradas, outras o foram tardiamente. Outras tantas não conseguiram emprego, não tiveram mais família, nem conseguiram constituir uma, ficaram relegadas à solidão. Algumas das que se casaram depois eram aconselhadas pelos esposos a não falarem sobre a guerra, não revelarem sua atuação no front, deixando velado um passado polêmico e não convencional. Um silenciamento imposto, seja pelos maridos, seja pela sociedade de forma mais ampla; por isso apenas tantos anos após os fatos vividos é que centenas dessas mulheres resolveram externalizar suas experiências e permitir os registros de suas memórias traumáticas. 


\section{REFERÊNCIAS BIBLIOGRÁFICAS}

ALEKSIÉVITCH, Svetlana. A guerra não tem rosto de mulher. Trad. Cecília Rosas. São Paulo: Companhia das Letras, 2016.

LEJEUNE, Philippe. O pacto autobiográfico: de Rousseau à Internet. trad. de Jovit Maria Gerheim Noronha e Maria Inês Coimbra Guedes, Belo Horizonte: Editora da UFMG, 2008

FOUCAULT, Michel. O que é um autor? Disponível em: http://disciplinas.stoa.usp.br/mod/res-ource/ view.php?id=105118. Acesso em 18 fev. 2019.

PADRÓS, Enrique Serra. Usos da Memória e do Esquecimento na História. Letras, nº 22: "Literatura e Autoritarismo", Santa Maria/RS, p. 79-95, jan./jun. 1991.

POLLAK, Michael. Memória e identidade social. Estudos Históricos, Rio de Janeiro, v. 5, no 10, 1992, p. 200-212. Disponível em: http://www.cpdoc.fgv.br/revista/arq/104.pdf; Acesso em: 18 Fev. 2019.

POLLAK, Michael. Memória, Esquecimento, Silêncio. Estudos Históricos, Rio de Janeiro, v. 2, nº 3, 1989, p. 3-15. Disponível em: http://www.cpdoc.fgv.br/revista/arq/43.pdf; Acesso em: 18 Fev. 2019.

SELIGMANN-SILVA, Márcio (org.). História, memória, literatura: o testemunho na era das catástrofes. Campinas: Editora da Unicamp, 2013. 
